\title{
BUSINESS MODEL INNOVATION FOR CIRCULAR ECONOMY: INTEGRATING LITERATURE AND PRACTICE INTO A CONCEPTUAL PROCESS MODEL
}

\author{
Pieroni, Marina de Padua; McAloone, Tim; Pigosso, Daniela \\ Technical University of Denmarkl
}

\begin{abstract}
A key question regarding business model innovation/development for circular economy is "how to make it happen in practice"? By systematically reviewing 92 approaches from circular economy and sustainability literature and practice, this research identifies requirements and proposes a holistic and systemic process for business model innovation for circular economy. This conceptual process model was consolidated based on the integration of the unique elements of sixteen existing process models. It comprises three-stages (sense, seize, transform) based on a dynamic capabilities view, and envisions 33 activities, 21 deliverables, 88 techniques/tools and 13 enablers or catalyzers for change. Besides enabling the view of processes and procedures with behavior and learning skills required to inspire circular economy thinking in business model innovation, it highlights the importance of 'formalized' decision-making procedures and includes activities to integrate sustainability thinking and to support the identification of required changes in product innovation/development.
\end{abstract}

Keywords: Circular economy, Sustainability, Business models and considerations, Process model

Contact:

Pieroni, Marina de Padua

Technical University of Denmark

Mechanical Engineering

Denmark

mdpp@dtu.dk

Cite this article: Pieroni, M.P., McAloone, T., Pigosso, D. (2019) 'Business Model Innovation for Circular Economy: Integrating Literature and Practice into a Conceptual Process Model', in Proceedings of the 22nd International Conference on Engineering Design (ICED19), Delft, The Netherlands, 5-8 August 2019. DOI:10.1017/dsi.2019.258 


\section{INTRODUCTION}

Circular economy $(\mathrm{CE})$ is often seen as one of the approaches to support the transition to a sustainable society (Geissdoerfer, Savaget, Bocken et al., 2017). CE, which appeared as an umbrella concept in the 2010's (Blomsma and Brennan, 2017), envisions the achievement of a more resource effective and efficient economic system by intentionally narrowing, slowing and 'ideally' closing materials and energy flows (Bocken et al., 2016).

Building capabilities for CE requires as much of organizational innovation as of technological or product innovation (Schulte, 2013). Hence, a growing stream of academic and industrial interest is emerging around the theme of business model innovation (BMI) towards enhanced circularity (Diaz Lopez et al., 2019; Pieroni et al., 2019). A business model (BMs) is the "design or architecture of the value creation, delivery, and capture mechanisms" of a business (Teece, 2010). In other words, they are 'mental constructs' that can be represented with visualisation tools to explain how a business work (Magretta, 2002). Business model innovation (BMI) are continuous organizational processes aiming to create, diversify, acquire or transform companies' business models (BMs) (Geissdoerfer et al., 2018) as a consequence of change triggers inside or outside the organizational boundaries (Foss and Saebi, 2017). BMI for circularity aims to uncover new ways of providing value to stakeholders (e.g. customers, suppliers) and exploring economic values along the products' life cycle to systemically boost resource efficiency and effectiveness (Den Hollander and Bakker, 2016).

Despite the observed excitement and the increasing development of methodological support for circularity-oriented BMI, the design and implementation of these new business models is still a challenge for companies (Blomsma and Brennan, 2017; Pieroni et al., 2019). Hence, a key question regarding BMI for CE is "how to make it happen in practice"? Inspired by a previous work that approaches resource-efficiency issues in product innovation (Brones and Monteiro de Carvalho, 2015), our hypothesis to answer to the former question is that there is a lack of 'integration' in CEoriented BMI practices, which is reflected both in literature and practice.

To contribute in finding answers for the aforementioned question, the objective of this article is to suggest a holistic (i.e. envisioning all stages of BMI from opportunities identification, design and implementation) and systemic (i.e. envisioning different processes' perspectives with technical and soft aspects) Business Model Innovation Process for CE. With a systematic literature review (section 2), this paper explores available approaches for BMI in CE and sustainability literature and identifies gaps associated with the lack of integration, as well as requirements to tackle those (section 3). Then, by consolidating the recurrent outcomes, activities, supporting techniques/tools, and change enablers of the existing process models, a new conceptual and generic process model is proposed to integrate CE principles in companies' BM innovation process and tackle the aprioristically identified integration gaps/challenges (section 4). Finally, a discussion is provided and the concluding remarks are presented (section 5).

\section{RESEARCH METHODOLOGY}

To propose the new business model innovation process for CE, a systematic review of literature was conducted with the purpose of answering two research questions:

- $\quad$ RQ1 - What are the existing process models to enable the integration of circular economy and business model innovation?

- $\quad$ RQ2 - What are the requirements and how to guide the development of a conceptual process model to leverage the integration of CE into BM innovation process in companies?

The review protocol was organized in data collection, data analysis and reporting (Biolchini et al., 2005; Tranfield et al., 2003) (Figure 1).

Data collection comprised search and selection of publications, in three steps. The first step focused on collecting academic BMI approaches (e.g. conceptual frameworks, methods and tools). The search originally performed by Pieroni et al. (2018) in Scopus and Web of Science in July 2017 that identified 10 process models/frameworks for CE-oriented BMI - was expanded to incorporate publications until July 2018 and to envision approaches from sustainability-oriented BMI. The reason for this expansion lies in the fact that the research stream 'sustainable business model innovation' also envisions resource efficiency and effectiveness principles and frequently considers CE as an archetype or strategy (Bocken et al., 2014; Pieroni et al., 2019). Hence, the search string applied to topic (title, keywords and abstract) 
was built to encompass both CE and sustainability approaches, as follows: ("circular economy" OR "circle economy" OR circularity OR circle OR circular OR "closed loops" OR "sustainable" OR sustainab*) AND "business models" AND (method OR tool OR framework OR approach OR methodology OR procedure OR technique OR canvas). This search resulted in 1078 unique publications. After removing duplicates, the authors screened title and abstracts applying a number of excluding criteria (BMI oriented to circularity/sustainability/resource efficiency explicitly addressed; information about the approaches including foundations and logic presented; generic and holistic approaches not addressing specific sectors or individual strategies of CE). This resulted in fifty-six publications for full content reading. The second step aimed to identify contributions from practitioners. Gray literature (Adams et al., 2017; Tranfield et al., 2003) and influential non-peerreviewed publications from non-profits organizations or knowledge platforms on CE/sustainability (such as the Ellen MacArthur Foundation and the Circular Economy Practitioner Guide published by the World Business Council for Sustainable Development; and the Knowledge Hub developed by Circle Economy) were investigated. Finally, the third step envisioned a snowballing approach (Wohlin, 2014) on the basis of initial selected publications (steps one and two) to capture the established and conceptual trends (through cross-reference). These two last steps increased the sample to ninety-four publications selected for analysis as documented in Pieroni et al. (2019).

Data analysis of the selected publications encompassed the definition of the information to be collected and the procedure for analysis. Content analysis and coding techniques (Dresch et al., 2015) were applied in three steps. In the first step, the authors identified publications presenting approaches with characteristics of process models/frameworks, i.e. a collection of organized and sequential activities that may be aggregated in phases or stages and supported by tools to perform a specific objective, which in this case is the development/innovation of business models for CE/sustainability (Pieroni et al., 2018). Furthermore, these approaches should cover several stages of the business model development process (e.g. ideation, conceptualization, implementation). The selected process models/frameworks were thoroughly analysed to enable the identification of their unique elements comprising stages, activities, outcomes, techniques/tools, implementation challenges, and enablers for change. Finally, gaps that emerged from their comparison allowed the identification of requirements for the proposition of an integrated process. These results are presented in section 3 .

As a second step, the process models/frameworks were integrated by unifying the terminology of stages, their unique elements and representation style. In the third step, a new conceptual process was proposed in order to fulfil the identified requirements (step 1) that could not be fully tackled with the integration of existing process models/frameworks (step 2). These results are presented in section 4.

Data collection

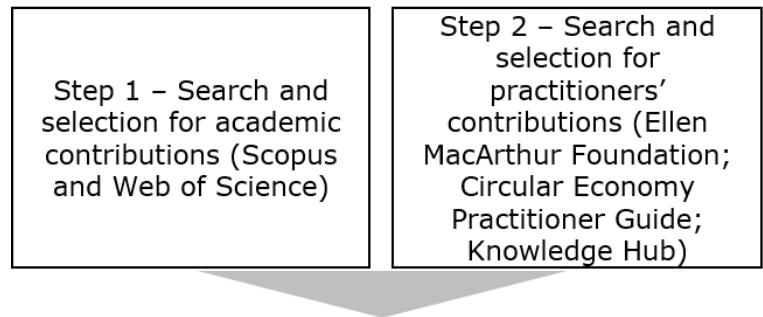

Step 3- Search and selection for established and conceptual trends (backwards snowballing/ crossreferencing)
Data analysis

[Data reporting]

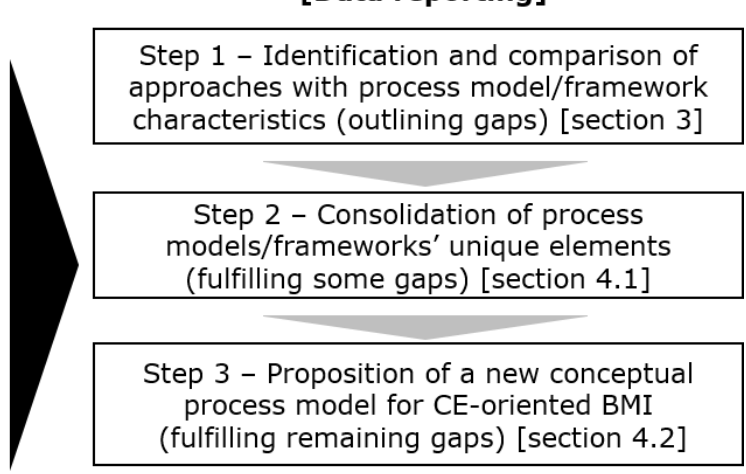

Figure 1 - Systematic review protocol.

\section{EXISTING PROCESS MODELS FOR CE-ORIENTED BUSINESS MODEL INNOVATION}

In respect to the research questions (section 2), this section provides answers for RQ1. The literature review identified sixteen process models for BMI for CE or sustainability (Table 1).

The process models/frameworks differ considerably in the content presented and the styles of representation. Some examples of differences in content comprise names for the stages/phases of BMI, and the elements for representing the processes, which varies from processes, activities or steps; 
expected deliverables, outcomes or outputs; gates or decision making procedures; applied techniques/tools; challenges; and enablers related to change management or normative aspects (i.e. behaviour, learning ability). Regarding the styles of representation, the process models/frameworks comprise both textual documents and visual representations (e.g. linear process flows, circular process flows, or innovation-like funnels).

Table 1 - Process models for business model innovation for CE or sustainability.

\begin{tabular}{|c|c|c|c|c|c|c|c|c|}
\hline Code & Process models & 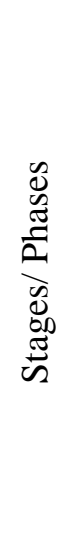 & 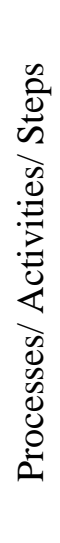 & 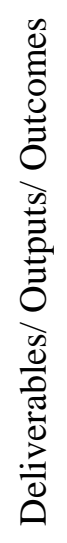 & 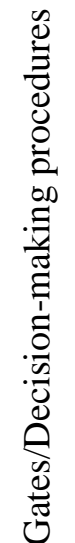 & 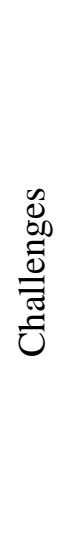 & 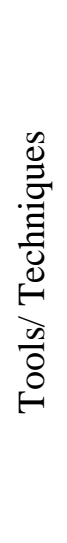 & 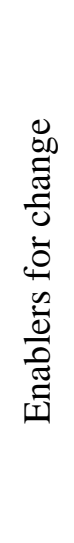 \\
\hline \multicolumn{9}{|c|}{ Circular Economy Focus } \\
\hline P01 & $\begin{array}{l}\text { Circular Business Model Innovation (CBMI) } \\
\text { Framework (Mentink, 2014) }\end{array}$ & $\mathrm{X}$ & & & & $\mathrm{X}$ & $\mathrm{X}$ & \\
\hline $\mathrm{P} 02$ & $\begin{array}{l}\text { Workbook 'Guided Choices towards a Circular } \\
\text { Business Model' (Joustra et al., 2013) }\end{array}$ & & $X$ & & & & $\mathrm{X}$ & \\
\hline P03 & $\begin{array}{l}\text { Workbook 'Realizing opportunities of a circular } \\
\text { business model' (de Jong et al., 2015) }\end{array}$ & & $X$ & & & & $X$ & \\
\hline P04 & $\begin{array}{l}\text { Circular Business Model Scan (van Renswoude et al., } \\
\text { 2015) }\end{array}$ & & $\mathrm{X}$ & $\mathrm{X}$ & & & $\mathrm{X}$ & \\
\hline P05 & $\begin{array}{l}\text { Guide for Suppliers Resource Efficient Business } \\
\text { Models (REBMs) (REBus, 2015) }\end{array}$ & $\mathrm{X}$ & $\mathrm{X}$ & $\mathrm{X}$ & & & $\mathrm{X}$ & \\
\hline P06 & $\begin{array}{l}\text { Circular Economy Business Toolkit (National Zero } \\
\text { Waste Council, 2016) }\end{array}$ & & $\mathrm{X}$ & & & & $\mathrm{X}$ & \\
\hline P07 & $\begin{array}{l}4 \text { steps towards a circular business strategy with the } \\
\text { value hill (Achterberg et al., 2016) }\end{array}$ & & $\mathrm{X}$ & & & & $\mathrm{X}$ & \\
\hline P08 & $\begin{array}{l}10 \text { steps towards a circular business (Kraaijenhagen } e t \\
\text { al., 2016) }\end{array}$ & & $\mathrm{X}$ & & & $\mathrm{X}$ & $\mathrm{X}$ & \\
\hline P09 & $\begin{array}{l}\text { Strategic process for implementation of circular } \\
\text { business models (Weetman, 2016) }\end{array}$ & & $\mathrm{X}$ & & & & $\mathrm{X}$ & \\
\hline P10 & $\begin{array}{l}\text { Backcasting and Eco-design for the Circular } \\
\text { Economy (BECE) Framework (Mendoza et al., 2017) }\end{array}$ & & $X$ & & & & $\mathrm{X}$ & \\
\hline P11 & $\begin{array}{l}\text { Business model innovation process in AARRE- } \\
\text { project (Antikainen et al., 2017) }\end{array}$ & & $\mathrm{X}$ & $\mathrm{X}$ & & & $\mathrm{X}$ & \\
\hline \multicolumn{9}{|c|}{ Sustainability Focus } \\
\hline P12 & $\begin{array}{l}\text { Stage-gate process for potential sustainable } \\
\text { innovation opportunities (Girotra and Netessine, } \\
\text { 2013) }\end{array}$ & $\mathrm{X}$ & $\mathrm{X}$ & & $\mathrm{X}$ & & $\mathrm{X}$ & \\
\hline P13 & Business modelling process (Holgado et al., 2013) & & $\mathrm{X}$ & $\mathrm{X}$ & & & & \\
\hline P14 & $\begin{array}{l}\text { A process model of business model change for } \\
\text { sustainability (Roome and Louche, 2016) }\end{array}$ & $\mathrm{X}$ & $\mathrm{X}$ & & & & & $\mathrm{X}$ \\
\hline $\mathrm{P} 15$ & $\begin{array}{l}\text { Framework for Strategic Sustainable Development } \\
\text { (FSSD) - BM Canvas approach (França et al., 2017) }\end{array}$ & & $\mathrm{X}$ & $X$ & & & $\mathrm{X}$ & \\
\hline P16 & $\begin{array}{l}\text { The Cambridge Business Model Innovation Process } \\
\text { (Geissdoerfer, Savaget and Evans, 2017) }\end{array}$ & $\mathrm{X}$ & $\mathrm{X}$ & & & $\mathrm{X}$ & & \\
\hline
\end{tabular}


Gaps in the existing process models (extracted from the publications or inferred by the researchers) could be identified, confirming the hypothesis of the 'lack of integration' mentioned in the Introduction section. This lack of integration occurs in four dimensions. The first dimension (D1), concerns the connections of CE-oriented BMI with the sustainability-oriented BMI. As uncovered by Mendoza et al. (2017), sustainability-oriented BMI process models still need to integrate CE principles and requirements consistently and systematically. Additionally, few CE-oriented process models (Antikainen et al., 2017; Kraaijenhagen et al., 2016) try to address the integrated vision and synergies of both concepts, such as for instance, verifying if the proposed CE BMs have the potential to contribute positively to sustainable development (which is not 'a given' as stated by Pieroni et al. (2018; 2019)).

The second dimension (D2) of integration relates to the idea that BMI is an on-going dynamic process of learning and change (Demil and Lecocq, 2010; Teece, 2010). Academic authors have flagged the absence of this view before. Geissdoerfer et al. (2017) pointed to a significant design-implementation gap around BMI for sustainability, and indicated the need for prescriptive guidance for companies in the format of reference process models. Only some process models envision all stages of the BMI process (Antikainen et al., 2017; Geissdoerfer, Savaget and Evans, 2017; Girotra and Netessine, 2013; Kraaijenhagen et al., 2016; Mentink, 2014; Roome and Louche, 2016).

The third dimension (D3) of integration is related to the idea that the decision making structure for BMI should be informed by CE values and mindset and reach all affected stakeholders, inside/outside the organizational boundaries. The role of concepts from social and behavioural sciences such as dynamic capabilities, normative management and change management is not explicitly integrated in circularity-oriented BMI literature (Ünal et al., 2018), although this is as relevant as having the right processes and tools in place (Andreasen, 2011; Roome and Louche, 2016). One process model (Roome and Louche, 2016) explored in details the phenomena of transformation of business models for sustainability, with a focus on normative and behavioural aspects. They highlighted some enabling factors (e.g. management engagement) that are fundamental for the change.

Finally, the fourth dimension (D4) of integration concerns the transdisciplinary characteristic of CE (Sakao and Brambila-Macias, 2018). Pieroni et al. (2018) identified that there is still disconnection in the extent to which CE-oriented business model innovation addresses the integration with other business processes in the organization - such as circular product design, collaboration and value chain management, information and communication technology - and exogenous change factors - such as legislation and infrastructure changes.

Besides these overall integration gaps, other specific challenges for individual BMI stages were identified (fully documented in Pieroni et al. (2019)):

- Preparation and Initiation: available techniques/tools are not entirely fulfilling learning needs about circular economy; lack of focus on the combination of several CE strategies (e.g. upgrade, reuse, remanufacturing, recycling) to propose the new BMs.

- Ideation and Integration: proposed techniques/tools are complex when compared to conventional tools (business as usual) and require high level of facilitation. In addition, they usually focus on single elements of the business model (e.g. value proposition or revenue streams). Finally, there is a lack of integration of sustainability principles in the design and assessment of business models for circular economy.

- Implementation: this stage is frequently overlooked, with a lack of tools/techniques to support it.

\section{CONSOLIDATION OF A NEW PROCESS FOR CE-ORIENTED BUSINESS MODEL INNOVATION}

This section presents the consolidation of existing process models and then introduces the new integrated conceptual process for CE-oriented BMI emerging from our findings. In respect to the research questions (section 2), this section provides answers for RQ2.

\subsubsection{Consolidation of the unique elements of existing process models}

From the analysis of gaps of the existing process models for CE-oriented BMI in literature and practice, a list of requirements (R) for developing a new CE-oriented BMI process was deployed:

- (R1) Explicit link of CE-oriented BMI and sustainability-oriented BMI;

- (R2) A holistic process addressing multiple stages of innovation - e.g. framing the CEtransformation strategy/vision, designing and implementing the new business models; 
- (R3) Explicit link of 'hard/technical' (i.e. processes/procedures/techniques) with 'soft/change management' (i.e. behaviour/learning abilities) aspects required for CE-oriented BMI;

- (R4) Transdisciplinary process, which indicates connections of the CE-oriented BMI and other innovation or business processes (i.e. product innovation).

In total, 33 activities, 21 deliverables, 88 techniques/tools and 13 enablers for change emerged from the consolidation of the 16 process models. Figure 2 describes the contribution of each process model to the stages of CE-oriented BMI. The percentage indicates the amount of activities of the specific process model incorporated into the consolidated Conceptual Process for CE-Oriented BMI.

\begin{tabular}{|c|c|c|c|c|c|c|c|c|c|c|c|c|c|c|c|c|}
\hline STAGES & P01 & P02 & P03 & P04 & P05 & P06 & P07 & P08 & P09 & P10 & P11 & P12 & P13 & P14 & P15 & P16 \\
\hline Preparation & $50 \%$ & $25 \%$ & $25 \%$ & $0 \%$ & $0 \%$ & $0 \%$ & $25 \%$ & $0 \%$ & $25 \%$ & $0 \%$ & $0 \%$ & $0 \%$ & $0 \%$ & $100 \%$ & $25 \%$ & $0 \%$ \\
\hline Immersion & $71 \%$ & $57 \%$ & $29 \%$ & $43 \%$ & $57 \%$ & $57 \%$ & $71 \%$ & $57 \%$ & $29 \%$ & $0 \%$ & $29 \%$ & $0 \%$ & $14 \%$ & $0 \%$ & $29 \%$ & $14 \%$ \\
\hline Ideation & $60 \%$ & $20 \%$ & $20 \%$ & $0 \%$ & $40 \%$ & $20 \%$ & $60 \%$ & $20 \%$ & $20 \%$ & $100 \%$ & $20 \%$ & $40 \%$ & $0 \%$ & $0 \%$ & $20 \%$ & $40 \%$ \\
\hline Integration & $57 \%$ & $57 \%$ & $43 \%$ & $0 \%$ & $0 \%$ & $0 \%$ & $43 \%$ & $29 \%$ & $29 \%$ & $29 \%$ & $14 \%$ & $43 \%$ & $14 \%$ & $43 \%$ & $29 \%$ & $43 \%$ \\
\hline Concept design & $50 \%$ & $50 \%$ & $50 \%$ & $0 \%$ & $0 \%$ & $0 \%$ & $50 \%$ & $0 \%$ & $50 \%$ & $0 \%$ & $0 \%$ & $50 \%$ & $0 \%$ & $50 \%$ & $50 \%$ & $100 \%$ \\
\hline Detailed design & $60 \%$ & $60 \%$ & $40 \%$ & $0 \%$ & $0 \%$ & $0 \%$ & $40 \%$ & $40 \%$ & $20 \%$ & $40 \%$ & $20 \%$ & $40 \%$ & $20 \%$ & $40 \%$ & $20 \%$ & $20 \%$ \\
\hline Implementation & $50 \%$ & $17 \%$ & $0 \%$ & $17 \%$ & $0 \%$ & $0 \%$ & $33 \%$ & $17 \%$ & $50 \%$ & $50 \%$ & $50 \%$ & $17 \%$ & $0 \%$ & $50 \%$ & $17 \%$ & $67 \%$ \\
\hline CONSOLIDATED VIEW & $53 \%$ & $35 \%$ & $21 \%$ & $15 \%$ & $18 \%$ & $15 \%$ & $47 \%$ & $26 \%$ & $29 \%$ & $32 \%$ & $21 \%$ & $18 \%$ & $9 \%$ & $32 \%$ & $24 \%$ & $32 \%$ \\
\hline
\end{tabular}

Figure 2- Contribution of each process model to the consolidated Conceptual Process for CE-Oriented BMI.

In order to select the unique elements from each process model, the BMI stages from the process proposed by Mentink (2014) (P01) were adopted as a starting reference point, because it is the most comprehensive in quantity of stages, comprising preparation, initiation, ideation, integration and implementation. Starting from this same process (P01), the remaining unique elements (i.e. activities, outcomes, techniques/tools, implementation challenges, enablers for change) were categorized according to their corresponding stages of BMI. Next, the remaining process models (P02-P16) were analysed in order to identify if they had the same elements as the previous ones (which was detected by semantic similarities) or comprised new elements. The new elements identified for each process model were added to the consolidated version.

The consolidation contributed to fulfilling the following requirements:

- $\quad R 1$ - Incorporation of tools for measuring sustainability performance (qualitatively) to support prioritizing or selecting circular economy business model concepts or solutions to be further detailed or implemented.

- $\quad R 2$ - The activities of the most comprehensive process model (P01) were complemented with activities from other process models in all stages (i.e. for each stage, there was at least one process model with a higher percentage composition than $\mathrm{P} 01$ ).

- $\quad R 4$ - Incorporation of activities and outcomes to outline the consequences of the strategic business model innovation decisions on product innovation strategies (during the CE business model concept design).

Requirement 3 (R3) could not be improved solely with the performed process of integration described in the previous sections. R3 is related to the role of concepts from social and behavioural sciences such as dynamic capabilities, normative management and change management as catalysers or enablers for the application of CE-oriented processes and tools. Although one process model (Roome and Louche, 2016) focused on behaviour and learning abilities aspects, the arrangement or terminology should be adapted and a new visual representation is required to facilitate the understanding and instantiation of the process in companies. That adaptation and new proposition, which emerged in the final process for CE-oriented BMI is explained in the following section.

\subsubsection{The new consolidated Conceptual Process for CE-Oriented Business Model Innovation}

The new Conceptual Process for CE-Oriented BMI is presented in Figure 3. To improve the integration dimension D3, a dynamic capability-based view (Inigo et al., 2017; Teece, 2007) was adopted as the reference framework. It includes three main stages, covering the entire activities of BMI and qualifying as a holistic approach: 
(1) Sense: consisting of opportunities' identification and generation of BM ideas for CE;

(2) Seize: comprising designing and testing new BM concepts/configurations for CE;

(3) Transform: building new competences and realizing organizational renewal to implement CEoriented BMs.

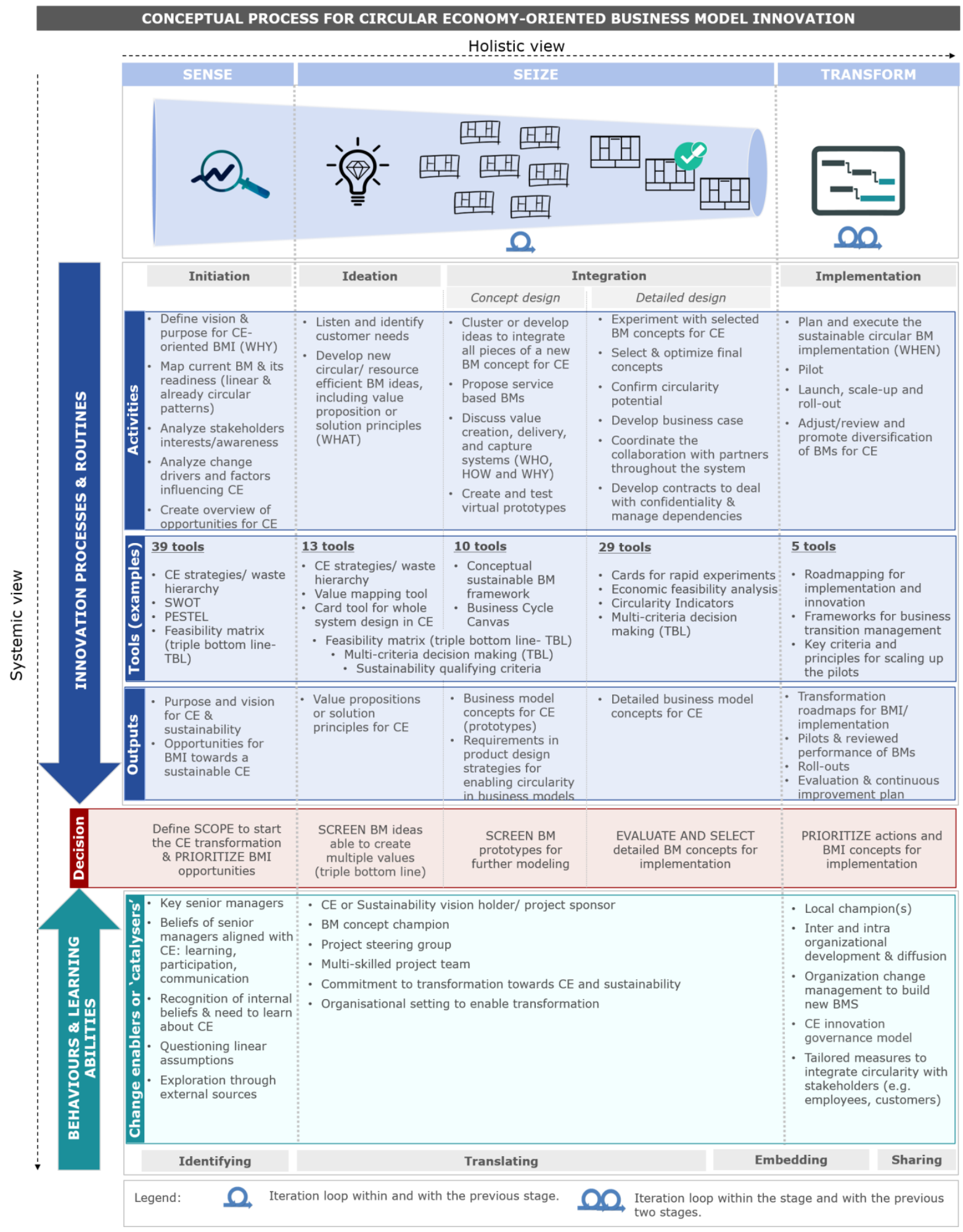

Figure 3 - Conceptual Process for CE-Oriented Business Model Innovation (BMI).

In addition to suggesting processes and routines to support the CE-oriented BM innovation management (Figure 3, dark blue arrow), this approach of dynamic-capabilities opens space for normative or change management aspects (e.g. values, mindset, behaviour, learning abilities), shedding light on how human-behaviour (represented by managers or decision makers) plays a role in CE-oriented BMI (Figure 3, green arrow). In our view, it represents more adequately the 'real world' 
phenomena, especially in transformational contexts such as sustainability and CE. It makes room to accommodate different types of innovation management approaches, focused on the 'hard or technical aspects of design' (e.g. P01, P16) and on the 'soft or transformational aspects' (e.g. P14), qualifying as a systemic approach.

As also illustrated in Figure 3 (blue loop-arrows), the Conceptual Process for CE-Oriented BMI is iterative regarding the stages Seize and Transform. This means that outputs of later phases may demand changes and revision of previous stages.

\section{CONCLUDING REMARKS}

This research aimed to propose a holistic and systemic process for CE-oriented BMI by integrating available approaches from literature and practice. By systematically reviewing 92 approaches, a new process was consolidated based on the integration of the unique elements of sixteen existing process models for sustainability/CE-oriented BMI. The process comprises three-stages (sense, seize, transform) based on a dynamic capabilities view. It contains 33 activities, 21 deliverables, 88 techniques/tools and 13 enablers for change. Besides enabling the holistic view of processes and procedures to guide all stages of BM innovation, it also allows for a systemic view with the indication of behaviour and learning skills required to stimulate CE-thinking or circularity-oriented innovation, 'formalized' decision-making procedures, and activities to integrate sustainability thinking (e.g. sustainability performance assessments) and product innovation strategies with the BMI activities.

Limitations of this research are related to the nature of the literature review techniques. Snowballing and the use of grey literature might generate selection bias. Moreover, many approaches used for the consolidation of the conceptual process are still being validated; therefore, their usefulness has not yet been confirmed in all cases. Additionally, the proposed process still needs to be verified in practice. This paper documents one of the initial steps of a comprehensive research to propose a CE-oriented BMI approach with a broader view of sustainability performance. This research is organized in three cycles (Figure 4) based on the hypothetico-deductive approach (Gill and Johnson, 2002).

The first research cycle gives continuity to the results presented in this paper. The proposed Conceptual Process for CE-Oriented BMI (with defined stages, outcomes, activities, supporting techniques/ tools, and enablers for change) will be complemented by the proposition or adaptation of stand-alone tools addressing specific BMI stages. These tools will be selected and adapted from the remaining 74 publications also identified in the systematic literature review (described in section 2 and documented in Pieroni et al. (2019)), or from the tools identified during the integration of the existing process models. This aims to tackle some of the aforementioned identified gaps/requirements in specific CE-oriented BMI stages (explained in section 3) that could not be fully addressed by the integration of the aprioristically presented process models. After that, the proposed process and the initially adapted tools from literature will be verified and refined in action research cycles with manufacturing companies (from different sizes, sectors and geographic regions). This will contribute to generate improvement opportunities to be applied in the second research cycle, when a new version of the process will be proposed, accompanied by customised management tools to tackle specific challenges of different organisational contexts or requirements not effectively addressed by the adaptations from existing tools. These new versions will be again verified and refined in action research cycles. After achieving a satisfactory version of the BMI approach for CE and its customized tools, case studies with a broader group of manufacturing companies will be conducted to validate the application and guidelines for adaptation of the approach in different organizational contexts. Lastly, the third research cycle will consolidate the improvements identified in cycle 2 to propose the final version of the approach (containing the process and accompanying customized tools) and a user guide. In addition to contributions to the research community with the generation of knowledge in the intersection of $\mathrm{CE}$, sustainability and BMI literature, envisioning the academic and practitioner perspectives, this work will also largely benefit organizations that are planning to engage in circular economy and need to define their strategy.

\section{ACKNOWLEDGEMENTS}

This article is one of the outcomes of the research project CIRCit (Circular Economy Integration in the Nordic Industry for Enhanced Sustainability and Competitiveness), which is part of the Nordic Green Growth Research and Innovation Programme (grant numbers: 83144) and supported by NordForsk, 
Nordic Energy Research, and Nordic Innovation. The authors would like to thank the CIRCit consortium for enriching discussions about $\mathrm{CE}$ and sustainability.

\section{REFERENCES}

Achterberg, E., Hinfelaar, J. and Bocken, N. (2016), "Master Circular Business With the Value Hill", https://www.circle-economy.com/wp-content/uploads/2016/09/finance-white-paper-20160923.pdf (accessed 15 July 2015).

Adams, R.J., Smart, P. and Huff, A.S. (2017), "Shades of Grey: Guidelines for Working with the Grey Literature in Systematic Reviews for Management and Organizational Studies", International Journal of Management Reviews, Vol. 19 No. 4, pp. 432-454. http://dx.doi.org/10.1111/ijmr.12102.

Andreasen, M.M. (2011), "45 Years with design methodology”, Journal of Engineering Design, Vol. 22 No. 5, pp. 293-332. http://dx.doi.org/10.1080/09544828.2010.538040.

Antikainen, M., Aminoff, A., Kettunen, O., Sundqvist-Andberg, H. and Paloheimo, H. (2017), "Circular Economy Business Model Innovation Process - Case Study”, In: Campana, G., Howlett, R.J., Setchi, R. and Cimatti, B. (Eds.), Sustainable Design and Manufacturing 2017, Vol. 68, Springer International Publishing, Cham, pp. 546-555, http://dx.doi.org/10.1007/978-3-319-57078-5_52.

Biolchini, J., Mian, P.G., Natali, A.C.C. and Travassos, G.H. (2005), Systematic Review in Software Engineering, [online] System Engineering and Computer Science Department COPPE/UFRJ, Rio de Janeiro, Available at: http://www.cos.ufrj.br/uploadfile/es67905.pdf (accessed 112 2017).

Blomsma, F. and Brennan, G. (2017), "The Emergence of Circular Economy: A New Framing Around Prolonging Resource Productivity”, Journal of Industrial Ecology, Vol. 21 No. 3, pp. 603-614. http://dx.doi.org/10.1111/jiec.12603.

Bocken, N.M.P., de Pauw, I., Bakker, C. and van der Grinten, B. (2016), "Product design and business model strategies for a circular economy", Journal of Industrial and Production Engineering, Vol. 33 No. 5, pp. 308-320. http://dx.doi.org/10.1080/21681015.2016.1172124.

Bocken, N.M.P., Short, S.W., Rana, P. and Evans, S. (2014), "A literature and practice review to develop sustainable business model archetypes", Journal of Cleaner Production, Elsevier Ltd, Vol. 65, pp. 42-56. http://dx.doi.org/10.1016/j.jclepro.2013.11.039.

Brones, F. and Monteiro de Carvalho, M. (2015), "From 50 to 1: integrating literature toward a systemic ecodesign model”, Journal of Cleaner Production, Elsevier Ltd, Vol. 96, pp. 44-57. http://dx.doi.org/10.1016/j.jclepro.2014.07.036.

Demil, B. and Lecocq, X. (2010), "Business Model Evolution: In Search of Dynamic Consistency", Long Range Planning, Vol. 43 No. 2-3, pp. 227-246. http://dx.doi.org/10.1016/j.lrp.2010.02.004.

Diaz Lopez, F.J., Bastein, T. and Tukker, A. (2019), "Business Model Innovation for Resource-efficiency, Circularity and Cleaner Production: What 143 Cases Tell Us", Ecological Economics, Elsevier, Vol. 155 No. March 2017, pp. 20-35. http://dx.doi.org/10.1016/j.ecolecon.2018.03.009.

Dresch, A., Lacerda, D.P. and Antunes Jr., J.A.V. (2015), Design Science Research, Springer International Publishing, Cham, Switzerland.

Foss, N.J. and Saebi, T. (2017), "Fifteen Years of Research on Business Model Innovation", Journal of Management, Vol. 43 No. 1, pp. 200-227. http://dx.doi.org/10.1177/0149206316675927.

França, C.L., Broman, G., Robèrt, K.-H., Basile, G. and Trygg, L. (2017), "An approach to business model innovation and design for strategic sustainable development", Journal of Cleaner Production, Vol. 140, pp. 155-166. http://dx.doi.org/10.1016/j.jclepro.2016.06.124.

Geissdoerfer, M., Savaget, P., Bocken, N.M.P. and Hultink, E.J. (2017), "The Circular Economy - A new sustainability paradigm?”, Journal of Cleaner Production, Vol. 143 No. January, pp. 757-768. http://dx.doi.org/10.1016/j.jclepro.2016.12.048.

Geissdoerfer, M., Savaget, P. and Evans, S. (2017), "The Cambridge Business Model Innovation Process", Procedia Manufacturing, The Author(s), Vol. 8 No. October 2016, pp. 262-269. http://dx.doi.org/10.1016/j.promfg.2017.02.033.

Geissdoerfer, M., Vladimirova, D. and Evans, S. (2018), "Sustainable business model innovation: A review", Journal of Cleaner Production, Elsevier Ltd, Vol. 198 No. under review, pp. 401-416. http://dx.doi.org/10.1016/j.jclepro.2018.06.240.

Gill, J. and Johnson, P. (2002), Research Methods for Managers, Sage Publications Ltd, London.

Girotra, K. and Netessine, S. (2013), "OM Forum - Business Model Innovation for Sustainability", Manufacturing and Service Operations Management, Vol. 15 No. 4, pp. 537-544. http://dx.doi.org/10.1287/msom.2013.0451

Holgado, M., Corti, D., Macchi, M., Rana, P., Short, S. and Evans, S. (2013), "Business Modelling for Sustainable Manufacturing", Advances in Production Management Systems. Competitive Manufacturing for Innovative Products and Services, pp. 166-174. http://dx.doi.org/10.1007/978-3-642-40352-1_22.

Den Hollander, M. and Bakker, C. (2016), "Mind the Gap Exploiter: Circular Business Models for Product Lifetime Extension", Proceedings of Electronic Goes Green 2016+, Fraunhofer IZM Berlin, Berlin, pp. 1-8. 
Inigo, E.A., Albareda, L. and Ritala, P. (2017), "Business model innovation for sustainability: exploring evolutionary and radical approaches through dynamic capabilities", Industry and Innovation, Routledge, Vol. 24 No. 5, pp. 515-542. http://dx.doi.org/10.1080/13662716.2017.1310034.

de Jong, E., Engelaer, F. and Morice, M. (2015), "Realizing opportunities of a circular business model", Available at http://images.info.yoursolutionspartner.com/Web/servicedllgroupcom/\%7Bee927947-b65e4360-a153-79b0f9ed68d7\%7D_Whitepaper_-

_Realizing_opportunities_of_a_circular_business_model.pdf?elqaid=71\&elqat=2\&elqTrackId=2f5d60d79 e744ee599ecea50b13497e9 (accessed172017).

Joustra, D.J., de Jong, E. and Engelaer, F. (2013), Guided Choices towards a Circular Business Model, http://www.c2cbizz.com/tools/c2c-bizz-guide-en.pdf\%0A (accessed 30 July 2017).

Kraaijenhagen, C., Van Open, C. and Bocken, N. (2016), Circular Business Collaborate and Circulate, Circular Collaboration, The Netherlands.

Magretta, J. (2002), Why Business Models Matter, Harvard Business Review, https://hbr.org/2002/05/whybusiness-models-matter (accessed 30 June 2018).

Mendoza, J.M.F., Sharmina, M., Gallego-Schmid, A., Heyes, G. and Azapagic, A. (2017), "Integrating Backcasting and Eco-Design for the Circular Economy: The BECE Framework", Journal of Industrial Ecology, Vol. 21 No. 3, pp. 526-544. http://dx.doi.org/10.1111/jiec.12590.

Mentink, B. A. S. (2014), Circular Business Model Innovation A Process Framework and a Tool for Business Model Innovation in a Circular Economy, Master Theis. Delft University of Technology and Leiden University.

National Zero Waste Council. (2016), Circular Economy Business Toolkit, National Zero Waste Council of Canada, http://www.nzwc.ca/Documents/CircularEconomyBusinessToolkit.pdf.

de Pádua P, M., Pigosso, D.C.A. and McAloone, T.C. (2018), "Sustainable Qualifying Criteria for Designing Circular Business Models”, Procedia CIRP, The Author(s), Vol. 69 No. May, pp. 799-804. http://dx.doi.org/10.1016/j.procir.2017.11.014.

Pieroni, M., Pigosso, D. and McAloone, T. (2018), "Exploring the synergistic relationships of circular business model development and product design", International Design Conference - Design 2018, pp. 2715-2726. http://dx.doi.org/10.21278/idc.2018.0202.

Pieroni, M.P.P., McAloone, T.C. and Pigosso, D.C.A. (2019), "Business model innovation for circular economy and sustainability: A review of approaches”, Journal of Cleaner Production, Vol. 215, pp. 198-216. http://dx.doi.org/10.1016/j.jclepro.2019.01.036.

REBus. (2015), Guide for Suppliers REBMs, http://www.rebus.eu.com/implementing-a-rebm/guide-forsuppliers-rebms/ (accessed 30 June 2018).

van Renswoude, K., ten Wolde, A. and Joustra, D.J. (2015), "Circular Business Models - Part 1: An Introduction to IMSA's Circular Business Model Scan", IMSA Amsterdam, http://hh.surfsharekit.nl:8080/get/smpid:53447/DS1 (accessed 20 July 2017).

Roome, N. and Louche, C. (2016), "Journeying Toward Business Models for Sustainability”, Organization and Environment, Vol. 29 No. 1, pp. 11-35. http://dx.doi.org/10.1177/1086026615595084.

Sakao, T. and Brambila-Macias, S.A. (2018), "Do we share an understanding of transdisciplinarity in environmental sustainability research?”, Journal of Cleaner Production, Vol. 170, pp. 1399-1403. http://dx.doi.org/10.1016/j.jclepro.2017.09.226.

Schulte, U.G. (2013), "New business models for a radical change in resource efficiency", Environmental Innovation and Societal Transitions, Elsevier B.V., Vol. 9, pp. 43-47. http://dx.doi.org/10.1016/j.eist.2013.09.006.

Teece, D.J. (2007), "Explicating dynamic capabilities: the nature and microfoundations of (sustainable) enterprise performance", Strategic Management Journal, Vol. 28 No. 13, pp. 1319-1350. http://dx.doi.org/10.1002/smj.640.

Teece, D.J. (2010), "Business Models, Business Strategy and Innovation”, Long Range Planning, Elsevier Ltd, Vol. 43 No. 2-3, pp. 172-194. http://dx.doi.org/10.1016/j.lrp.2009.07.003.

Tranfield, D., Denyer, D. and Smart, P. (2003), "Towards a Methodology for Developing Evidence-Informed Management Knowledge by Means of Systematic Review”, British Journal of Management, Vol. 14 No. 3, pp. 207-222. http://dx.doi.org/10.1111/1467-8551.00375.

Ünal, E., Urbinati, A. and Chiaroni, D. (2018), "Managerial practices for designing circular economy business models", Journal of Manufacturing Technology Management, p. JMTM-02-2018-0061. http://dx.doi.org/10.1108/JMTM-02-2018-0061.

Weetman, C. (2016), A Circular Economy Handbook for Business and Supply Chains: Repair, Remake, Redesign, Rethink., Kogan Page Publishers, New York.

Wohlin, C. (2014), "Guidelines for snowballing in systematic literature studies and a replication in software engineering", Proceedings of the 18th International Conference on Evaluation and Assessment in Software Engineering - EASE '14, ACM Press, New York, New York, USA, pp. 1-10. http://dx.doi.org/10.1145/2601248.2601268. 